\title{
Transformation of Monochromatic Waves from Deep to Shallow Water
}

by

Bernard Le Mehaute and John D. Wang

\section{TECHNICAL REPORT NO. 80-2}

\section{AUGUST 1980}

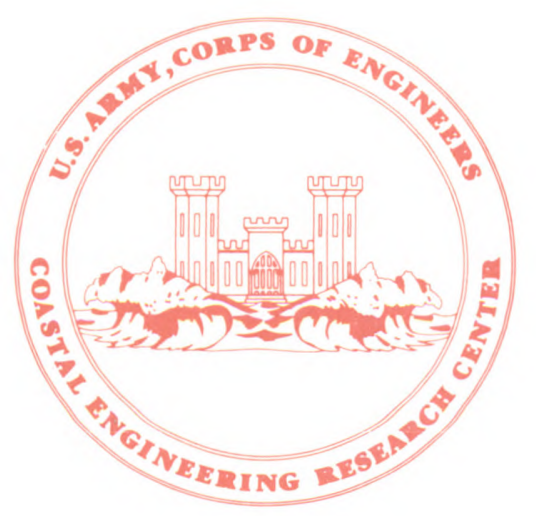

Approved for public release;

distribution unlimited.

\section{Prepared for \\ U.S. ARMY, CORPS OF ENGINEERS \\ COASTAL ENGINEERING \\ RESEARCH CENTER \\ Kingman Building \\ Fort Belvoir, Va. 22060}

UNIVERSITY OF MICHIGAN 